Proceedings

\title{
Techno-Functional Properties of New Andean Ingredients: Maca (Lepidium meyenii) and Amaranth (Amaranthus caudatus) ${ }^{\dagger}$
}

\author{
Miguel Angel Alarcón-García 1,** , Jose Angel Perez-Alvarez 2,* , Jairo Humberto López-Vargas ${ }^{3}$ and \\ Maria Jesús Pagán-Moreno ${ }^{1}$
}

Citation: Alarcón-García, M.A.; Perez-Alvarez, J.A.; López-Vargas, J.H.; Pagán-Moreno, M.J. TechnoFunctional Properties of New Andean Ingredients: Maca (Lepidium meyenii) and Amaranth (Amaranthus caudatus). Proceedings 2021, 70, 74. https://doi.org/10.3390/foods_202007744

Published: 10 November 2020

Publisher's Note: MDPI stays neutral with regard to jurisdictional claims in published maps and institutional affiliations.

Copyright: $\odot 2020$ by the authors. Licensee MDPI, Basel, Switzerland. This article is an open access article distributed under the terms and conditions of the Creative Commons Attribution (CC BY) license (http://creativecommons.org/licenses/by/4.0/).
1 CUINA Food Research and Innovation Group, Food Technology Department, Universitat Politecnica de Valencia, Camino de Vera s/n, 46022 Valencia, Spain; jpagan@tal.upv.es

2 IPOA Research Group, Agri-Food Technology Department, Universidad Miguel Hernández (UMH), Carretera de Beniel, Km. 3,2, 03312 Orihuela, Spain

3 Instituto de Ciencia y Tecnología de Alimentos (ICTA), Universidad Nacional de Colombia, Sede Bogotá, Ac. 26 \#40-85, 111321 Bogotá, Colombia; jhlopezv@unal.edu.co

* Correspondence: mialgar7@upv.edu.es (M.A.A.-G.); ja.perez@goumh.umh.es (J.A.P.-A.)

+ Presented at the 1st International Electronic Conference on Food Science and Functional Foods, 10-25 November 2020; Available online: https://foods_2020.sciforum.net/.

\begin{abstract}
The use of flours derived from Andean products could be an alternative flour. Molecules with a potential beneficial effect on human health have been reported in maca (Lepidium meyenii) (dietary fibre, $\mathrm{Mg}, \mathrm{Ca}, \mathrm{K}$, functional polysaccharides, etc.) and amaranth (Amaranthus caudatus) (squalene, linoleic acid, $\mathrm{P}, \mathrm{Ca}, \mathrm{K}, \mathrm{Mg}$, dietary fibre, etc.). However, from an industrial point of view, these new ingredients must be characterized in their techno-functional properties. The objective of this work was to analyze the techno-functional parameters of the amaranth and maca flours (NW) and whole (W) flours, in terms of water holding capacity (WHC, g/g), oil holding capacity (OHC, $\mathrm{g} / \mathrm{g}$ ), swelling capacity (SC, mL/g), foaming capacity (FC, \%) and emulsifying capacity (EC, $\mathrm{mL}$ ). The particle size of flours was also analyzed. The results indicated that the highest values for WHC were obtained in maca flour (NW) with $2.45 \mathrm{~g}$ of retained water/g of sample. The highest values of $\mathrm{OHC}$ were observed for NW flours (around $1.02 \mathrm{~g}$ of absorbed oil/g of sample). Meanwhile, for the variables FC and EC, the highest values were obtained for amaranth (NW) with $16.67 \%$ and amaranth (W) with $139.44 \mathrm{~mL}$, respectively. Therefore, the results obtained allow us to consider the incorporation of these types of flours to different food products, knowing their effect on WHC, $\mathrm{OHC}, \mathrm{EC}$, and $\mathrm{pH}$, and therefore being able to modify the processes concerning the traditional ones. This is especially interesting in the case of the meat products elaboration process in which these parameters could be critical, with the addition of these type of flours.
\end{abstract}

Keywords: healthy meat products; maca; amaranth; water holding capacity; oil holding capacity

\section{Introduction}

The Andean highlands are located in native areas over $4000 \mathrm{~m}$ altitude where crops show a significant resistance under hostile environmental conditions [1]. However, they have been associated to indigenous local Andean people due to the wisdom and extraordinary nutritional features [1]. Consumption of Andean highlands crops take place, in general, after heat treatment and milled. The most common treatments in amaranth (Amaranthus cuadatus) and maca (Lepidium meyenii) cases are roasting and drying, respectively. However, maca is also consumed as a fresh food either [2,3]. Further, foods as soups, beverages, pasta, jams, puddings, and others have traditional manufacturing methods that 
include Andean milled foods as ingredients in the formulations $[2,4,5]$. The high nutritional value and its contents of bioactive compounds have been demonstrated; this would allow conferring functional properties to the foods in which they are incorporated. Thus, it has been reported that maca has a low level of fat, high level of protein, up to $21 \%$, with the presence of seven out of ten essential amino acids (2.2\%), and is a source of minerals $(\mathrm{Ca}, \mathrm{Mg}, \mathrm{K})[6]$. It contains dietary fiber in a range of 15.6 to $26 \%$ [7]. Further, a wide variety of potential functional molecules included glucosinolates, functional polysaccharides, alkamides [3,8], and antioxidant and anti-inflammatory compounds have been reported [9].

On the other hand, high amaranth's nutritional value is based mainly on minerals $(\mathrm{P}$, $\mathrm{Ca}, \mathrm{K}, \mathrm{Mg}$ ) [10], vitamins (E, B2, C), antioxidant compounds as polyphenols [11], dietary fiber (up to $20 \%$ ), and protein (16\%) levels. Essential amino acids lysine, methionine, and cysteine are contained in their amino acid profile [11,12]. Some studies indicate that amaranth oil contains cholesterol-lowering and anticancer precursors such as squalene (up to $8 \%$ of total unsaturated fatty acids) [12] and unsaturated fatty acids with a high $\Omega 6$ content that can range from 40 to $55 \%$ of the total unsaturated fatty acids [5]. Therefore, maca and amaranth are potential ingredients to enhance processed food formulations. However, the additional processes could promote different technological challenges, such as physicochemical, textural, sensory, and techno-functional deficiencies. In this context, the evaluation of the techno-functional properties of these potential ingredients is necessary to develop new processed food formulations. The aim of this work was to evaluate, and the main functional properties of wholemeal (W) and nonwholemeal (NW) maca and amaranth flours in terms of their adding processed food aptitude.

\section{Materials and Methods}

\subsection{Plant Materials}

Maca (Lepidium meyenii) and amaranth (Amaranthus caudatus) as wholemeal (W) and nonwholemeal (NW) flours were obtained from local markets in the Valencian community, Spain.

\subsection{Techno-Functional Properties}

The water holding capacity (WHC) and the oil holding capacity (OHC) were measured following the procedure of $\mathrm{Wu}$ et al. [13]. Briefly, $1 \mathrm{~g}$ of each flour was mixed with $10 \mathrm{~mL}$ of distilled water or oil and the mixture was vortexed for $1 \mathrm{~min}$, allowed to stand for $30 \mathrm{~min}$, and centrifuged at $5000 \mathrm{~g}$ for $30 \mathrm{~min}$. Excess liquid was removed, the supernatant was decanted, and the pellet tube was weighed with retained water or oil. The results were expressed as the amount of water or oil retained per one gram of the sample. Both procedures were performed in triplicate for each sample. The solubility index (SI) was obtained by measuring the soluble components in the excess liquid from each WHC test. For this purpose, the samples were first dried at $70{ }^{\circ} \mathrm{C}(4 \mathrm{~h})$ to avoid liquid projections and then a second drying step at $105{ }^{\circ} \mathrm{C}$ to a constant weight. The results were expressed as the amount of soluble compounds per gram of sample. The SI procedure was performed in triplicate for each sample.

Swelling capacity (SC) was determined following the method of Robertson et al. [14] with minor modifications. Briefly, $600 \mathrm{mg}$ were weighted in a graduated tube, excess water was added, and the sample was dispersed with gentle stirring and then allowed to stand for $18 \mathrm{~h}$. Results were calculated by volume sample difference, before and after water added, and expressed as $\mathrm{mL} / \mathrm{g}$ of sample. The procedure was performed in triplicate for every sample.

Emulsifying capacity (EC) and emulsion stability (ES) were determined following the method of Sathe and Salunkhe [15] with minor modifications. Briefly, $250 \mathrm{mg}$ of sample, $12.5 \mathrm{~mL}$ of water, and $1 \mathrm{~mL}$ of oil were homogenized with an Ultra-Turrax at the speed of $15,000 \mathrm{rpm} / 30 \mathrm{~s}$. The oil addition was discontinued when an oil layer was observed de- 
spite the mechanical stirring. EC results were expressed as $\mathrm{mL}$ of oil emulsified/g of sample. Meanwhile, it was allowed to stand for $24 \mathrm{~h}$ and then $\mathrm{mL}$ of water released were determined to express the ES ( $\mathrm{mL}$ of water released/24 h). The SC and ES procedures were performed in triplicate for every sample.

Foaming capacity (FC) and foam stability (FS) were determined following the method of Shevkani et al. [16]. Briefly, the sample suspension $(1 \% w / v, 30 \mathrm{~mL})$ at $7.00 \mathrm{pH}$ adjusted in a graduated cylinder was homogenized with an Ultra-Turrax at 15,000 rpm/2 min. FC was expressed as the percentage of increased volume. Meanwhile, it was allowed to stand for $30 \mathrm{~min}$ and then FS was determined and expressed as percentage remained foam. The FC and FS procedures were performed in triplicate for every sample.

\subsection{Particle Size}

Particle size was determined with dry method applied with Mastersizer 2000 equipment. It applies a low angle laser light scattering with a $466 \mathrm{~nm}$ length wave for determining the average particle size ( $\mathrm{D}(4,3))$. Results were expressed using $\mathrm{nm}$ as units. This procedure was performed in triplicate for every sample.

\subsection{Statistical Analysis}

A completely randomized design was used, and the results were analyzed by using a one-way analyses of variance (One-Way ANOVA). A Tukey's post hoc test was used to determine the differences between the mean values for different variables in each flour $(p<0.05)$. All these analyses were performed using Statgraphics Centurion XVII (Madrid, Spain).

\section{Results and Discussion}

The Figure 1 shows the results for the hydration-related parameters, water holding capacity (WHC). Solubility index (SI) and swelling capacity (SC) showed significant differences $(p<0.05)$ between all the samples, except for the SC where no significant differences $(p>0.05)$ were observed between the whole meal $(\mathrm{W})$ and nonwhole meal (NW) maca flours samples. For all parameters, maca flours showed higher values than amaranth flours $(p>0.05)$. When comparing $\mathrm{W}$ and NW samples, the behavior fluctuated depending on the variable analyzed. For swelling capacity (SC), the values were of the same order in the case of maca samples $(p>0.05)$. For amaranth, the highest values were for $\mathrm{W}$ samples.

Values of hydration properties have been reported in different studies for maca and amaranth flours. For amaranth, the values reported were $3.48(\mathrm{~g} / \mathrm{g}), 5.07(\%)$, and 3.32 $(\mathrm{mL} / \mathrm{g})$ for WHC [17], SI [18], and SC [19], respectively, while for maca values reported were $8.39(\mathrm{~g} / \mathrm{g}), 20(\%)$ and $12.33(\mathrm{~mL} / \mathrm{g})$ for WHC [20], SI [13], and SC [19,21], respectively.

The different results obtained in this work may be partially explained by the particle size of flours. Thus, small sizes have been related to an increase in hydration properties. It is due to a bigger surface area and volume pore. The results of particle size indicated that amaranth flours showed the mayor values of particle size, with significant differences $(p<0.05)$ between $W$ flours, with a size of $327.17 \pm 17.18$ and $157.25 \pm 3.57 \mu \mathrm{m}$ for amaranth and maca, respectively. In contrast, NW flours showed insignificant differences $(p>0.05)$ between them, with size particles of $128.53 \pm 1.45$ and $128.08 \pm 0.90 \mu \mathrm{m}$ for amaranth and maca, respectively. Hydration variables indicate the interaction between flours and water; they are the result of hydrophilic and hydrophobic groups' balance. WHC has an impact on food formulations because it can be used to eschew syneresis effects, which is very important in meat products. Hence, controlling WHC allows modulating physicochemical properties related to the food texture [13]. In addition, other variables such as $\mathrm{pH}$ (5.26 $\pm 0.02,5.30 \pm 0.01,6.54 \pm 0.01,6.88 \pm 0.02$ for NW maca, W maca, NW amaranth, W amaranth, respectively), particle size, pore-volume, etc., weigh on hydration properties.

Oil holding capacity is the ability of powder ingredients for remaining oil while a gravity force can affect the flavor sensation and the mouthfeel. Furthermore, it depends on nonpolar groups' presence in terms of quantity and their interaction with fat [13]. This 
parameter is related to other properties as the emulsifying capacity and its stability. Figure 2 shows that OHC values were higher $(p<0.05)$ for NW flours with respect to $\mathrm{W}(p<0.05)$. These results agree with studies that point out the refined process as a cause of the increase of OHC $[17,20,21]$. Thus, NW maca flours with fiber-rich fractions and NW amaranth flour with protein-rich fraction presented $\mathrm{OHC}$ values 3.91 and $6.40 \mathrm{~g} / \mathrm{g}$, respectively. However, the results obtained in this work are similar to $\mathrm{OHC}$ values reported for other Andean flours, such as quinoa, with a range from 0.89 to $1.2 \mathrm{~g} / \mathrm{g}$ depending on the variety plant [20-22].

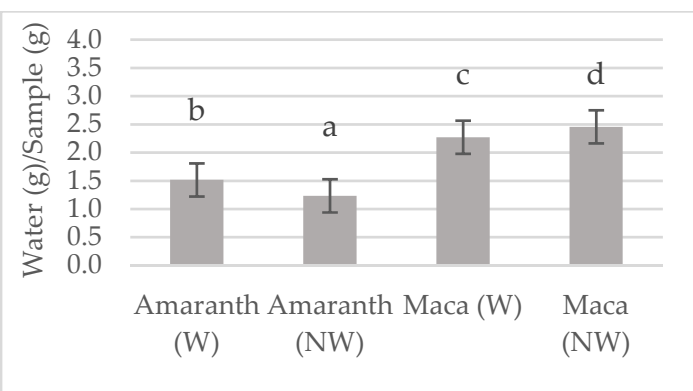

(a)

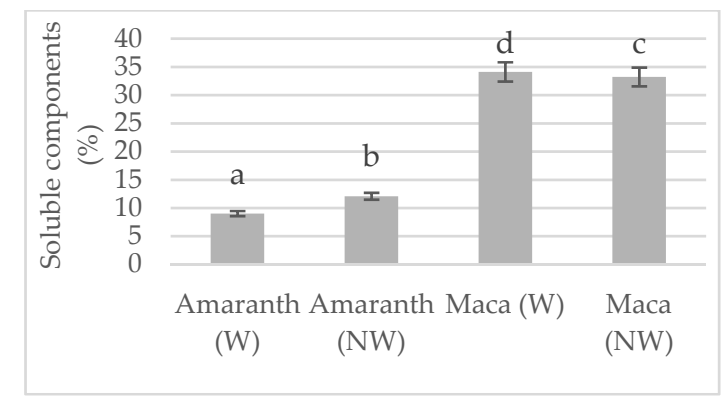

(b)

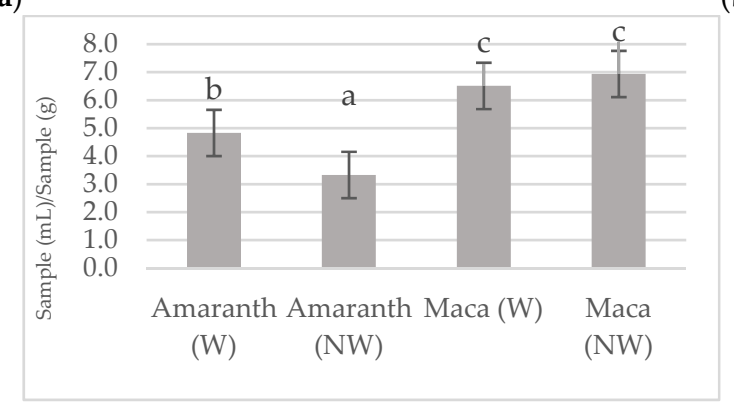

(c)

Figure 1. (a) Water holding capacity (WHC), (b) solubility index (SI) and (c) swelling capacity (SC) values of whole meal (W) and nonwhole meal (NW) maca and amaranth flours. ${ }^{*}$ Means with the same letter do not differ significantly $(p>$ $0.05)$.

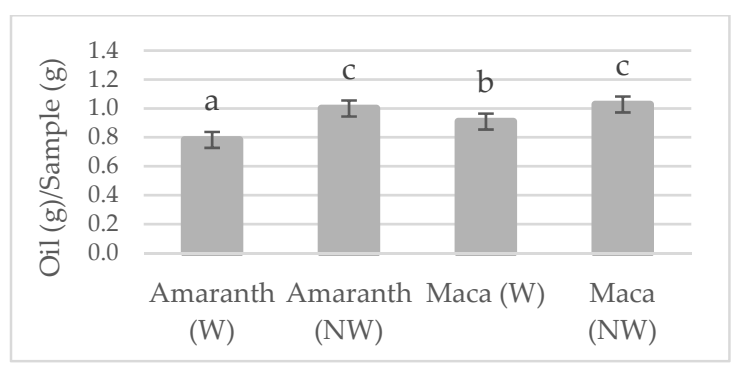

Figure 2. Oil holding capacity $(\mathrm{OHC})$ values of $\mathrm{W}$ and NW maca and amaranth flours. ${ }^{*}$ Means with the same letter do not differ significantly $(p>0.05)$. The results of the emulsion properties of studied flours are shown in Figure 3.

With respect to emulsifying capacity (EC), no significant differences were detected between NW amaranth and W maca $(p<0.05)$. W Amaranth flour presented the highest values, and NW maca presented the lowest. For the emulsion stability properties (ES), insignificant differences were detected between maca samples and amaranth $\mathrm{W}$ sample, in all cases, with values around $40 \mathrm{~mL}$ (water released at $24 \mathrm{~h}$ ). On the other hand, ES values of amaranth NW were much lower. The values of the emulsion variables indicate the ability of the ingredients to reduce surface tension and facilitate the creation of stable structures over time, avoiding phenomena such as coalescence. Studies with flour and protein concentrate of Phaseolus vulgaris L. indicate values of EC of 39.6 and $72.6 \mathrm{~mL}$ of emulsified oil/g of sample and values of ES of $26 \mathrm{~mL}$ of released water/g, whereas with 
protein concentrate the release of water was of $0 \mathrm{~mL} / \mathrm{g}$ [15]. In this case, $\mathrm{W}$ amaranth flour showed higher values for EC than legume flours, whereas W and NW maca and amaranth NW flours display similar and lower values. Regarding ES, analyzed samples presented values higher than those indicated for legume flours, except NW amaranth whose values were slightly lower.

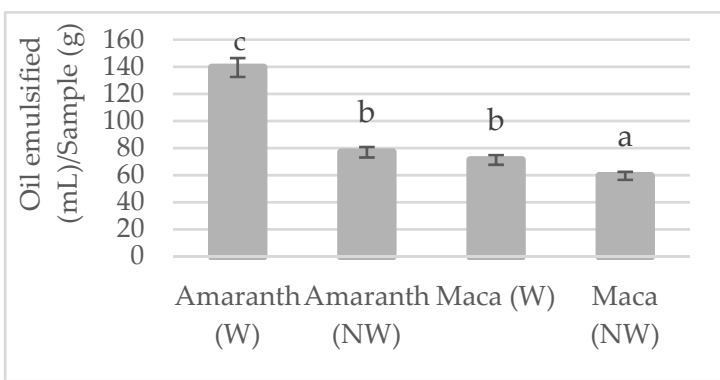

(a)

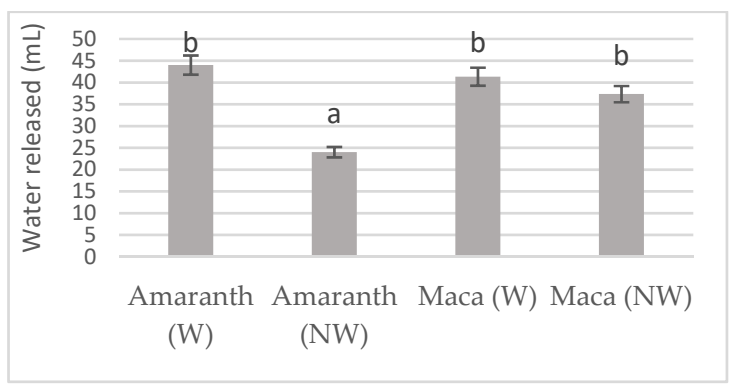

(b)

Figure 3. (a) Emulsifying capacity (EC) and (b) emulsion stability at $24 \mathrm{~h}(\mathrm{ES})$ values of whole meal (W) and non whole meal (NW) maca and amaranth flours. ${ }^{*}$ Means with the same letter do not differ significantly $(p>0.05)$.

The results of foaming capacity (FC) and stability (FS) are shown in Figure 4. NW amaranth flour obtained the highest values for both properties with significant differences $(p<0.05)$, while for both properties the W and NW maca flours did not show significant differences $(p>0.05)$. The results observed for the FC variable in maca flours were similar to those mentioned for quinoa flour with values of the order of $9 \%$ FC. In the case of amaranth flour, these were somewhat lower. Regarding the variable FS, the values obtained differ from those mentioned for the quinoa (4\%) [23]. However, quinoa flour has been suggested as a substitute for wheat flour in milkshakes due to its FC [24]. Therefore, the results obtained would allow considering the use of maca and amaranth flours $\mathrm{W}$ and NW in this type of products. In any case, it will be necessary to evaluate how the addition of amaranth and maca could modify a processed food since reformulations can change the appearance and other variables related to consumer expectations of a known food.

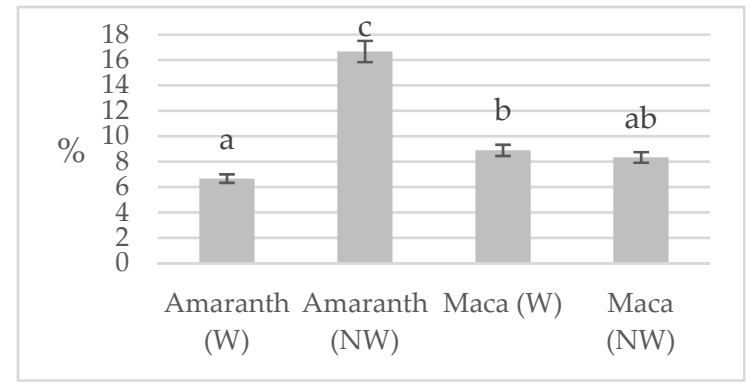

(a)

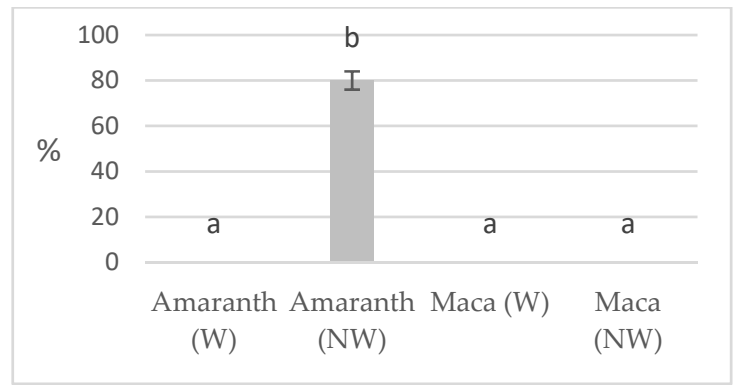

(b)

Figure 4. (a) Foaming capacity (FC) and (b) foam stability at $30 \mathrm{~min}$ (FS) values of $\mathrm{W}$ and NW maca and amaranth flours. ${ }^{*}$ Means with the same letter do not differ significantly $(p>0.05)$.

\section{Conclusions}

The results obtained allow us to consider incorporating these types of flours to different food products, knowing their effect on WHC, OHC, and EC, and therefore being able to modify the processes concerning the traditional ones. This is especially interesting in the case of the meat products elaboration process in which these parameters could be critical, with the addition of these types of flours. 
Author Contributions: Conceptualization, M.A.A.-G., M.J.P.-M., and J.A.P.-A.; methodology, M.A.A.-G.; validation, M.A.A.-G., M.J.P.-M., and J.A.P.-A.; formal analysis, M.A.A.-G.; investigation, M.A.A.-G., M.J.P.-M., and J.A.P.-A.; resources, J.H.L.-V.; data curation, M.A.A.-G.; writingoriginal draft preparation, M.A.A.-G.; writing - review and editing, M.J.P.-M. and J.A.P.-A.; supervision, M.J.P.-M. and J.A.P.-A.; project administration, M.J.P.-M., J.A.P.-A., and J.H.L.-V. All authors have read and agreed to the published version of the manuscript.

Funding: Not applicable.

Institutional Review Board Statement: Not applicable.

Informed Consent Statement: Not applicable.

Data Availability Statement: The data presented in this study are available on request from the corresponding author.

Acknowledgments: Authors thank to "Colombia Científica" Initiative with "Pasaporte a la Ciencia: Doctorado" program for providing the scholarship to Miguel Angel Alarcón-García.

Conflicts of Interest: The authors declare no conflicts of interest.

\section{References}

1. Loyer, J.; Knight, C. Selling the "Inca superfood": Nutritional primitivism in superfoods books and maca marketing. Food Cult. Soc. 2018, 21, 449-467, doi:10.1080/15528014.2018.1480645.

2. Shevkani, K.; Singh, N.; Kaur, A.; Rana, J.C. Physicochemical, Pasting, and Functional Properties of Amaranth Seed Flours: Effects of Lipids Removal. J. Food Sci. 2014, 79, C1271-C1277, doi:10.1111/1750-3841.12493.

3. Chain, F.E.; Grau, A.; Martins, J.; Catalan, C.A. Macamides from wild 'Maca', Lepidium meyenii Walpers (Brassicaceae). Phytochem. Lett. 2014, 8, 145-148, doi:10.1016/j.phytol.2014.03.005.

4. Zhao, J.; Muhammad, I.; Dunbar, D.C.; Mustafa, J.; Khan, I.A. New Alkamides from Maca (Lepidium meyenii). J. Agric. Food Chem. 2005, 53, 690-693, doi:10.1021/jf048529t.

5. Corke, H.; Cai, Y.Z.; Wu, H.X. Amaranth: Overview. In Reference Module in Food Science; Elsevier B.V.: Amsterdam, The Netherlands, 2016; pp. 287-296.

6. Li, J.; Chen, L.; Li, J.; Duan, Z.; Zhu, S.; Fan, L. The Composition Analysis of Maca (Lepidium meyenii Walp.) from Xinjiang and Its Antifatigue Activity. J. Food Qual. 2017, 2017, 2904951, doi:10.1155/2017/2904951.

7. Wang, S.; Zhu, F. Chemical composition and health effects of maca (Lepidium meyenii). Food Chem. 2019, 288, 422-443, doi:10.1016/j.foodchem.2019.02.071.

8. Korkmaz, S. Antioxidants in Maca (Lepidium meyenii) as a Supplement Supplement in in Nutrition Nutrition. In Antioxidants in Foods and Its Applications; Shalaby, E., Ghada, G., Eds.; IntechOpen: London, UK, 2018; pp. 137-154.

9. Chen, L.; Li, J.; Fan, L. The Nutritional Composition of Maca in Hypocotyls (Lepidium meyenii Walp.) Cultivated in Different Regions of China. J. Food Qual. 2017, 2017, 3749627, doi:10.1155/2017/3749627.

10. Kachiguma, N.A.; Mwase, W.; Maliro, M.; Damaliphetsa, A. Chemical and Mineral Composition of Amaranth (Amaranthus L.) Species Collected from Central Malawi. J. Food Res. 2015, 4, 92, doi:10.5539/jfr.v4n4p92.

11. Tamsen, M.; Shekarchizadeh, H.; Soltanizadeh, N. Evaluation of wheat flour substitution with amaranth flour on chicken nugget properties. LWT 2018, 91, 580-587, doi:10.1016/j.lwt.2018.02.001.

12. Singh, N.; Singh, P.; Shevkani, K.; Virdi, A.S. Amaranth: Potential Source for Flour Enrichment. In Flour and Breads and Their Fortification in Health and Disease Prevention; Elsevier B.V.: Amsterdam, The Netherlands, 2019; pp. $123-135$.

13. Zhang, M.; Zhang, M.; Xin, X.; Lai, F.; Wu, H. Physicochemical and functional properties of a protein isolate from maca (Lepidium meyenii) and the secondary structure and immunomodulatory activity of its major protein component. Food Funct. 2019, 10, 2894-2905, doi:10.1039/c8fo02490a.

14. Robertson, J.A.; De Monredon, F.D.; Dysseler, P.; Guillon, F.; Amado, R.; Thibault, J.-F. Hydration Properties of Dietary Fibre and Resistant Starch: A European Collaborative Study. LWT 2000, 33, 72-79, doi:10.1006/fstl.1999.0595.

15. Sathe, S.K.; Salunkhe, D.K. Functional Properties of the Great Northern Bean (Phaseolus vulgaris L.) Proteins: Emulsion, Foaming, Viscosity, and Gelation Properties. J. Food Sci. 1981, 46, 71-81, doi:10.1111/j.1365-2621.1981.tb14533.x.

16. Shevkani, K.; Singh, N.; Kaur, A.; Rana, J.C. Structural and functional characterization of kidney bean and field pea protein isolates: A comparative study. Food Hydrocoll. 2015, 43, 679-689, doi:10.1016/j.foodhyd.2014.07.024.

17. Chauhan, A.; Saxena, D.; Singh, S. Total dietary fibre and antioxidant activity of gluten free cookies made from raw and germinated amaranth (Amaranthus spp.) flour. LWT 2015, 63, 939-945, doi:10.1016/j.lwt.2015.03.115.

18. Cornejo, F.; Novillo, G.; Villacrés, E.; Rosell, C.M. Evaluation of the physicochemical and nutritional changes in two amaranth species (Amaranthus quitensis and Amaranthus caudatus) after germination. Food Res. Int. 2019, 121, 933-939, doi:10.1016/j.foodres.2019.01.022.

19. Paredes-López, O.; Schevenin, M.L.; Hernández-López, D.; Cárabez-Trejo, A. Amaranth Starch-Isolation and Partial Characterization. Starch Stärke 1989, 41, 205-207, doi:10.1002/star.19890410602. 
20. Shevkani, K.; Singh, N.; Rana, J.C.; Kaur, A. Relationship between physicochemical and functional properties of amaranth (Amaranthus hypochondriacus) protein isolates. Int. J. Food Sci. Technol. 2013, 49, 541-550, doi:10.1111/ijfs.12335.

21. Chen, J.; Zhao, Q.; Wang, L.; Zha, S.; Zhang, L.; Zhao, B. Physicochemical and functional properties of dietary fiber from maca (Lepidium meyenii Walp.) liquor residue. Carbohydr. Polym. 2015, 132, 509-512, doi:10.1016/j.carbpol.2015.06.079.

22. Pellegrini, M.; Lucas-Gonzales, R.; Ricci, A.; Fontecha, J.; Fernández-López, J.; Pérez-Álvarez, J.A.; Viuda-Martos, M. Chemical, fatty acid, polyphenolic profile, techno-functional and antioxidant properties of flours obtained from quinoa (Chenopodium quinoa Willd) seeds. Ind. Crops Prod. 2018, 111, 38-46, doi:10.1016/j.indcrop.2017.10.006.

23. James, L.E.A. Chapter 1 Quinoa (Chenopodium quinoa Willd.). In Advances in Food and Nutrition Research; Elsevier B.V.: Amsterdam, The Netherlands, 2009; Volume 58, pp. 1-31.

24. Romano, N.; Ureta, M.M.; Guerrero-Sánchez, M.; Gómez-Zavaglia, A. Nutritional and technological properties of a quinoa (Chenopodium quinoa Willd.) spray-dried powdered extract. Food Res. Int. 2020, 129, 108884, doi:10.1016/j.foodres.2019.108884. 